\title{
BMJ Open Quality Rapid quality improvement in a preterm birth clinic care pathway during the COVID-19 pandemic
}

To cite: Zarasvand S, Bayar E, Adan M, et al. Rapid quality improvement in a preterm birth clinic care pathway during the COVID-19 pandemic. BMJ Open Quality 2020;9:e001049. doi:10.1136/ bmjoq-2020-001049

Received 15 June 2020 Revised 3 December 2020 Accepted 10 December 2020

Check for updates

(C) Author(s) (or their employer(s)) 2020. Re-use permitted under CC BY-NC. No commercial re-use. See rights and permissions. Published by BMJ.

${ }^{1}$ Imperial College Healthcare NHS Trust, London, UK ${ }^{2}$ Imperial College London, London, UK

${ }^{3}$ March of Dimes European Preterm Birth Research Centre, Imperial College London, London, UK

Correspondence to Dr Lynne Sykes;

I.sykes@imperial.ac.uk

\section{ABSTRACT}

Background Preterm birth (PTB) occurs in $8 \%$ of births in the UK. At Imperial College Healthcare NHS Trust, our PTB prevention clinic manages the care of approximately 1000 women/year. Women referred to the clinic are seen from 12 weeks of pregnancy with subsequent appointments every $2-4$ weeks to measure cervical length $(\mathrm{CL})$ using transvaginal ultrasound (TVUS). Women with a history of cervical weakness or short cervix on TVUS are offered a cervical cerclage.

Local problem During the COVID-19 outbreak, pregnant women were strongly advised to avoid social mixing and public transport. The National Health Service had to rapidly adopt remote consultation and redesign clinical pathways in order to reduce transmission, exposure and spread among women at high risk of PTB.

Methods We focused on Specific, Measurable, Achievable, Realistic and Timebound aims and used a driver diagram to visualise our changes. We used a series of Plan Do Study Act cycles to evaluate and adapt change ideas through the UK's national lockdown during the COVID-19 pandemic between 23 March and 29 May 2020.

Results We reduced the number of face-to-face appointments by $54 \%$. This was achieved by increasing remote telephone consultations from $0 \%$ to $64 \%$, and by reducing the intensity of surveillance. The rate of regional anaesthetic was increased from $53 \%$ to $95 \%$ for cerclage placement in order to minimise the number of aerosolgenerating procedures. Patient and staff satisfaction responses to these changes were used to tailor practices. No women tested positive for COVID-19 during the study period.

Conclusions By using quality improvement methodology, we were able to safely and rapidly implement a new care pathway for women at high risk of PTB which was acceptable to patients and staff, and effective in reducing exposure of COVID-19.

\section{PROBLEM}

Imperial College Healthcare NHS Trust serves an inner London community that is ethnically diverse and densely populated. The combined delivery rate of St Mary's Hospital (SMH) and Queen Charlotte's and Chelsea Hospital (QCCH) is roughly 8500 per year, with a preterm birth (PTB) rate of approximately $7.8 \%$. The PTB prevention clinic sees approximately 1000 new women a year who are at risk of spontaneous preterm birth (sPTB). It is designed to predict and prevent sPTB through the use of targeted screening tools including serial transvaginal cervical length (CL) scanning, and targeted surgical intervention with history or ultrasound indicated (CL $<25 \mathrm{~mm})$ cervical cerclage. In addition, the service also provides emotional support and continuity of care with designated named specialist doctors and midwives within the team.

COVID-19 was first identified in the UK on 31 January 2020 and a global pandemic was declared by WHO on 11 March $2020 .{ }^{1}$ By mid-March, Public Health England had announced that pregnant women should be included in the vulnerable groups and issued guidance on social distancing. Pregnant women were strongly advised to avoid social mixing in the community, avoid public transport where possible and to access the National Health Service (NHS) remotely. ${ }^{2}$ A week later, a national lockdown was issued on 23 March 2020 in the UK, leading to school closures and home working, in an attempt to significantly reduce the transmission of the virus.

Our concern for our women at high risk of sPTB was that the high-intensity surveillance in the preterm prevention clinic could lead to increased exposure, transmission and spread of the coronavirus via:

- the use of public transport to attend the clinics;

- social interactions in a confined and busy clinic waiting area;

- attendance with children that would have been in nursery/school;

- attendance with partners for emotional support.

Our Specific, Measurable, Achievable, Realistic and Timebound (SMART) objectives for this study were to minimise potential 
exposure of patients to COVID-19, measured by an achievable and realistic target of reducing face-to-face (FTF) contact of patients and their families, timebound by the rapid response needed to the pandemic. We had a second SMART objective relating to reducing the use of general anaesthetic (GA) for cervical cerclage procedures, due to the higher risk of spreading COVID-19 through the aerosol-generating GA procedure. This was a specific aim to encourage a GA rather than regional anaesthetic, easily measurable, achievable and realistic with the help of stakeholders' input (patients and staff opinions). It was also a timebound goal that relied on the Plan Do Study Act (PDSA) cycle to support its implementation and sustainability.

\section{BACKGROUND}

SARS-COV-2, the novel coronavirus that causes COVID-19 was first identified in Wuhan, China at the end of December 2019 and was recognised to cause more severe symptoms and carry a higher mortality rate. ${ }^{3}$ When WHO announced a global pandemic at the beginning of March, limited information was available on the effect of COVID-19 in pregnancy. However, other coronaviruses such as SARS-CoV and Middle East respiratory syndrome had led to high fatality rates in pregnant women, $15 \%$ and $27 \%$, respectively. ${ }^{4}$ With estimates of infection rate being approximately $80 \%$ in an unmitigated response to the epidemic in the $\mathrm{UK},{ }^{5}$ it was clear that we needed to rapidly adapt our care pathway for managing women at high risk of sPTB in order to reduce maternal morbidity and mortality.

PTB describes the birth of a baby before $37+0$ weeks of gestation and is the leading cause of mortality in children under the age of 5 worldwide. ${ }^{6}$ In 2016, the Secretary of State for Health set a target to reduce PTB in the UK from $8 \%$ to $6 \%$, with a focus on three areas to improve outcome: predication, prevention and preparation in cases of unavoidable PTB. The Saving Babies Lives Care Bundle V.2 recommends NHS units provide care for women at risk of PTB, ideally via a prevention clinic where transvaginal ultrasound (TVUS) can be performed for risk assessment with the option to provide cervical cerclage as a preventative measure. ${ }^{7}$ The guidance recommends a risk assessment is conducted at booking to identify women at risk early and facilitate referral to the prevention services by 12 weeks of pregnancy. It recommends that women at high risk of SPTB (defined by previous $\mathrm{PTB} /$ preterm prelabour rupture of membranes (PPROM) $<34$ weeks, mid-trimester loss (MTL), previous cerclage, known congenital uterine anomaly (CUA), previous trachelectomy) are offered TVUS every 2-4 weeks up until 24 weeks of pregnancy as a minimum standard of care. Additionally, women at intermediate risk of PTB (defined as previous cervical excisional treatment $>10 \mathrm{~mm}$ or previous fully dilated caesarean section (FDCS) ) are offered at least two TVUS between 18 and 22 weeks and again at 24 weeks.
Our trust care pathway has the capacity to offer more intense surveillance and included a wider referral criterion for those at risk of sPTB compared with the recommended minimum standard of care in the Saving Babies Lives Care Bundle V.2 guidance. Our pathway used a threshold for previous PTB/PPROM of $<37$ weeks. It also included women with any significant excisional cervical treatments regardless of depth, women with a previous surgical termination or surgical management of miscarriage beyond 16 weeks. Our surveillance was more frequent, with the first TVUS at 12-14 weeks of pregnancy and continuing up to 28 weeks. Appointments were 1-4 weeks apart, depending on CL and history.

As the COVID-19 pandemic was announced, advice on the management of pregnant women with suspected and confirmed COVID-19 was released by the Royal College of Obstetricians and Gynaecologists. ${ }^{3}$ However, it was only at the time of lockdown that guidance was issued for adapting routine antenatal care pathways. ${ }^{8}$ The guideline recommended the rapid establishment of remote consultations, a reduction in the number of FTF appointments and the introduction of streamlined appointments.

NHS England issued guidance on how to continue implementing two of the five elements of the Saving Babies Lives Care Bundle V.2 during the outbreak, including guidance on fetal growth surveillance and carbon monoxide monitoring in pregnancy. ${ }^{9}{ }^{10}$ However, Element 5, prevention of PTB, was not addressed during the lockdown period, driving the development of a local protocol to streamline care. Our preterm prevention team joined with the maternity QI leads at Imperial College Healthcare Trust to design and implement a new PTB care pathway. The primary aim was to reduce exposure, transmission and spread while maintaining highquality care for women at risk of sPTB. Specific aims were to reduce the number of referrals by $16 \%$ (an estimate reached from baseline data by including only the women at highest risk of sPTB, figure 1), minimise surveillance frequency and ultimately to reduce FTF consultations by $20 \%$.

\section{METHODS AND DESIGN}

We used quality improvement (QI) methodology to design and evaluate our change ideas. In particular:

- Stakeholder engagement (see 'Patient and public involvement' section);

- Process mapping of the patient journey in order to identify potential non-value added steps that could be eliminated;

- Identifying key drivers and using a driver diagram to define our measures;

- Successive PDSA cycles and rapid cycles of improvement;

- Sustaining and spreading successful changes.

We reported on routinely collected clinical data which were anonymised at the point of analysis. 
A

\begin{tabular}{|l|c|c|c|c|}
\hline & $\begin{array}{l}\text { Pre COVID-19 } \\
\text { 10 weeks }\end{array}$ & $\begin{array}{l}\text { COVID-19 outbreak } \\
\text { 10 weeks }\end{array}$ & \% change & P value \\
\hline $\begin{array}{l}\text { Number of all } \\
\text { referrals }\end{array}$ & 179 & 259 & $+44.70 \%$ & n/a \\
\hline $\begin{array}{l}\text { Inappropriate } \\
\text { referrals } \\
\text { received }\end{array}$ & $24 / 179(15.48 \%)$ & $38 / 259(14.67 \%)$ & $-0.81 \%$ & 0.78 \\
\hline $\begin{array}{l}\text { Percentage } \\
\text { inappropriate } \\
\text { referrals seen } \\
\text { FTF }\end{array}$ & $\begin{array}{l}24 / 24 \\
(100 \%)\end{array}$ & $\begin{array}{l}1 / 38 \\
2.63 \%)\end{array}$ & -97.37 & $<0.0001$ \\
\hline Bisk factors pre COVID-19 & C Risk factors during COVID-19 & \\
\hline
\end{tabular}

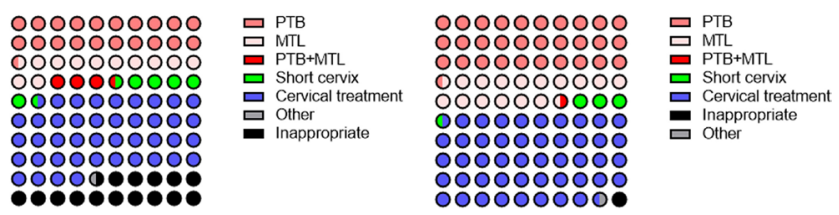

Figure 1 Reduction of inappropriate new referrals being seen in the preterm prevention clinic during the COVID-19 outbreak. During the COVID-19 outbreak, we saw an increase in referrals to the preterm prevention clinic. However, although the percentage of inappropriate referrals did not change, we significantly reduced the numbers that were seen face to face (FTF) (100\%-2.63\%) (A). Furthermore, clinician-directed vetting of new referrals led to an increased proportion of women at highest risk of preterm birth (PTB) being seen FTF from $41.5 \%$ (B) to $50.5 \%(C)$ as shown in the dotblot. Statistical analysis was performed using the Fisher's exact test ( $n=438)$. MTL, mid-trimester loss; $n / a$, not available.

\section{Patient and public involvement}

A random selection of study participants were selected, as well as the Imperial Patients as Partners patient and public involvement (PPI) group, to answer study questionnaires and to provide information on our balancing measures. Clinic participants and PPI members were given anonymised questionnaires to help with service evaluation and informed consent was obtained. Results will be disseminated in the form of a poster displayed in the clinic area. Box 1 includes questions that were asked to participants, PPI group members and staff.

\section{Measurement}

An altered care pathway with a refined referral criteria, reduced surveillance intensity and the introduction of remote consultations was created during the week prior to the government lockdown. Baseline measurements were taken retrospectively from a 3-month period. The reasons for referral, number of referrals and FTF consultations were noted, in order to set realistic, measurable and achievable targets for reducing FTF consultations. The altered care pathway was designed by the preterm prevention team, sanctioned by the Trust's guidelines committee, and distributed via the Trust's intranet. Copies were emailed to all maternity staff and provided to clinical areas.

Following the introduction of our new care pathway, the following outcome measures were collected, analysed and discussed weekly by the preterm prevention team and the QI team:

- Total number of consultations;
Box 1 Stakeholder engagement: Questions asked in form of questionnaire

Patient and patient and public involvement group

- During the COVID-19 outbreak, would you prefer to have a remote consultation if your doctor feels it is appropriate? (Answer optionsyes, no, no preference)

- During the COVID-19 outbreak, if you are offered a remote consultation, would you prefer a telephone or video consultation; or do you have no preference?

- When the COVID-19 outbreak is declared to be over, and if doctors feel it is safe to have a remote consultation instead of face to face, which kind of consultation would you prefer? (Answer optionsface to face, telephone, video, no preference).

- If you have been given a remote consultation appointment, would you prefer-a specified appointment time, specified session or no preference.

- In the event of requiring a cerclage, which form of anaesthetic would you prefer-a regional anaesthetic or a general anaesthetic.

\section{Staff questions}

- Overall, do you think the adjusted pathway has helped to minimise the spread of COVID-19 within women who are at higher risk of spontaneous preterm birth? (Answer options on scale of 1-5, yes $=1, \mathrm{no}=5$ )

- Do you think that the new pathway is reducing workload for the preterm prevention team? (Answer options-yes, no, I do not know)

- Do you think that the new pathway is effective in identifying women who may require therapeutic intervention? (Answer options-scale of $1-5$, yes $=1$, no $=5$ )

> Overall, do you think that the adjusted pathway, with less intense surveillance, has increased anxiety levels for our patients? (Answer options-yes in some, yes in most, yes in all, no)

- Are there any improvements that you can think of that we could introduce to the COVID-19 pathway?

- Would you prefer remote consultations to be video, phone or no preference?

- Once the COVID-19 outbreak is declared to be over, do you think we would benefit to continue some appointments as remote consultations? (Answer options-yes, no, no preference) If so, in which format would you prefer?

- Once the COVID-19 outbreak is declared to be over, what aspects of the COVID-19 pathway would you like to keep?

- Number of FTF and remote consultations;

- Number of new referrals;

- Number of cervical cerclages performed.

We collected the following process measures to help understand the factors impacting the fluctuations in FTF consultations per week, and on the procedural aspects of cervical cerclage insertion:

- Number of inappropriate referrals made;

- Number of inappropriate FTF clinic appointments;

- Number of remote consultations per clinic;

- Cross-site staffing activity;

- Indications for cervical cerclage;

- Number of operative lists required for cerclages.

Inappropriate referrals were grouped as referrals received for women with risk factors no longer cited in the modified referral criteria, that is, history of excisional 
cervical treatment $<10 \mathrm{~mm}$ depth, previous FDCS, CUA and previous PTB $>34 / 40$, iatrogenic PTB; or any factor not known to increase the risk of SPTB.

To ensure that the introduction of this new care pathway did not lead to any adverse outcomes or patient/ staff dissatisfaction, the following balancing measures were collected:

- Intervention rates of clinic patients;

- Patient experience via questionnaires;

- Clinician experience via questionnaires and regular remote meetings;

- MTL rate of clinic patients;

- PTB rate of clinic patients.

\section{Design}

We registered the project with the Corporate Patient Safety and Effectiveness team and created a COVID-19 action team comprising the preterm prevention team including six obstetricians and two midwives with a specialist interest in PTB, and two obstetricians with a specialist interest in QI. The preterm prevention team designed the new care pathway using information collected from the baseline measurements, national guidelines and an up-to-date literature search on the use of CL monitoring and cervical cerclage for women at risk of sPTB. We had weekly remote meetings within the preterm prevention team and with the maternity QI team in order to ensure continued improvement in the implementation of the new care pathway.

\section{Strategy}

In view of establishing a 'Quality Improvement Preterm Prevention Guideline', we created a record of all the women in each clinic who received a telephone or FTF appointment, the nature and number of referrals and new patients we saw each week and logged the number of cervical cerclages completed with details of anaesthetic used GA or spinal anaesthetic (SA). Each week we conferred across sites to review patient and staff feedback and the PDSA cycles described in table 1 .

\section{RESULTS}

Table 2 shows the altered referral criteria and table 3 summarises the surveillance schedule for the preterm prevention clinic. This was followed between 23 March and 29 May. We performed PDSA cycles (table 1) to evaluate the rapid implementation of the new care pathway. Within this 10-week period, there were two clinics at each site per week (three clinics were cancelled due to bank holidays/staffing). Baseline data were retrospectively collected from clinics in a 10 -week period prior to COVID-19 between 25 November and 27 January. For fair comparison, this included two clinics at each site per week and three cancelled clinics.

\section{Change in appointment scheduling: referrals and frequency}

During the design phase of the altered care pathway, a literature search was performed to capture the most significant risk factors for $\mathrm{SPTB}$ and to review the evidence supporting CL monitoring and cerclage insertion according to risk factor for PTB. The referral criteria was consequently amended to exclude women with a previous FDCS and known CUA. The threshold for previous PTB meeting our referral criteria was reduced from 37 to $<34$ weeks. We aimed to reduce referrals by $16 \%$ by excluding these women and inappropriate referrals. Contrary to expected, new referrals increased by $44.7 \%$, from 179 to 259 from the period we studied prior to COVID-19. Additionally, our inappropriate referral percentage remained unchanged at roughly $15 \%$ (figure 1). Our PDSA (A) cycle (table 1) detected that inappropriate referrals were still being made and led to a change in process of the introduction of specialist clinicians to screen all referrals prior to booking an appointment. Following this intervention, and combined with the introduction of telephone consultations, this led to an overall reduction in new inappropriate referrals seen FTF from $100 \%$ to $2.63 \%$ (figure $1 \mathrm{~A}$ ). Additionally, and with the use of the PDSA cycles A and B (table 1), we demonstrate in the dotblots that our COVID-19-adapted clinics saw a greater proportion of women of the highest risk of PTB (those with a history of PTB/MTL/short cervix) and a much lower proportion of lowest risk women ('other') (figure 1B,C).

When PDSA (C) cycle (table 1) was performed, we identified the need to re-establish FTF follow ups for women who had received cerclages. This was due to the increased number of telephone calls to the maternity helpline and the prematurity team from women who were anxious to be seen in the clinic to obtain a CL measurement for reassurance. We also reinstated women with a previous FDCS into the referral criteria following identification of a woman with a previous FDCS and found to have a short cervix $(6 \mathrm{~mm})$ at a routine anomaly scan who needed an emergency cervical cerclage.

\section{Change in appointment scheduling: reduction in FTF consultations}

Contrary to what we anticipated, the total number of clinic consultations increased by $10 \%$ during the study period when compared with the baseline pre-COVID-19 study period (figure 2A). However, the absolute number of FTF consultations reduced significantly from 341 to 157 (figure 2A), with a mean number of FTF visits reducing from 34.1 (red line) to 15.1 (red dotted line) visits per week (figure 2B and $\mathrm{C}$ ). The run chart also shows the number of total, FTF and telephone consultations in the baseline pre-COVID-19 period, week 1-10 (figure 2B) and during the COVID-19 outbreak, week 11-20 (figure 2C). The percentage reduction in FTF appointments was $54 \%$ which greatly exceeded our initial target of $20 \%$. The percentage increase in telephone consultations increased from $0 \%$ to $64.4 \%$.

Results from our staff and patient questionnaire were used to guide our PDSA cycles (table 1) and support patient acceptability for remote consultations. The 
Table 1 Summary of Plan Do Study Act (PDSA cycles)

\begin{tabular}{|c|c|c|c|c|}
\hline & Plan & Do & Study & Act \\
\hline $\begin{array}{l}\text { PDSA cycle A: } \\
\text { referral criteria }\end{array}$ & $\begin{array}{l}\text { We wanted to reduce } \\
\text { numbers of referrals, aiming, } \\
\text { to prioritise women at high } \\
\text { risk of PTB by reviewing up- } \\
\text { to-date published literature } \\
\text { and national guidelines. }\end{array}$ & $\begin{array}{l}\text { Remove lower risk criteria } \\
\text { and/or risk factors whereby } \\
\text { CL screening and cervical } \\
\text { cerclage are of uncertain } \\
\text { or limited benefit. The } \\
\text { following risk factors were } \\
\text { consequently removed from } \\
\text { the referral criteria; previous } \\
\text { FDCS, uterine anomaly, } \\
\text { previous punch biopsy or } \\
\text { trachelectomy. }\end{array}$ & $\begin{array}{l}\text { We found that simply } \\
\text { publicising a revised } \\
\text { referral criteria did } \\
\text { not reduce the } \\
\text { number of referrals. } \\
\text { We also had one } \\
\text { woman who required } \\
\text { an emergency } \\
\text { cervical cerclage and } \\
\text { her only risk factor } \\
\text { for sPTB was a } \\
\text { previous FDCS. }\end{array}$ & $\begin{array}{l}\text { Introduced a vetting clinician to } \\
\text { screen all referrals. } \\
\text { We reinstated women with a } \\
\text { previous FDCS into the referral } \\
\text { criteria. }\end{array}$ \\
\hline $\begin{array}{l}\text { PDSA cycle B: } \\
\text { referral vetting }\end{array}$ & $\begin{array}{l}\text { We thought vetting would } \\
\text { reduce the number of } \\
\text { women attending the clinic } \\
\text { FTF. }\end{array}$ & $\begin{array}{l}\text { All referrals were vetted by } \\
\text { a clinician who accepted/ } \\
\text { rejected the referral and } \\
\text { decided on type and timing } \\
\text { of appointment (remote or } \\
\text { FTF). }\end{array}$ & $\begin{array}{l}\text { The number of } \\
\text { FTF appointments } \\
\text { decreased and the } \\
\text { number of remote } \\
\text { consultations } \\
\text { increased. The } \\
\text { vetting process was } \\
\text { time consuming for } \\
\text { the vetting clinician. }\end{array}$ & $\begin{array}{l}\text { If this process was to be } \\
\text { continued in the longer term, } \\
\text { more efficient processes could } \\
\text { be tried, but the clinician time } \\
\text { was thought to be well spent as } \\
\text { the intervention was successful } \\
\text { in reducing FTF consultations in } \\
\text { the COVID-19 pandemic period }\end{array}$ \\
\hline $\begin{array}{l}\text { PDSA cycle } \\
\text { C: intensity of } \\
\text { surveillance }\end{array}$ & $\begin{array}{l}\text { We thought we could } \\
\text { reduce the number of } \\
\text { unessential hospital visits } \\
\text { following cerclages. }\end{array}$ & $\begin{array}{l}\text { We used telephone } \\
\text { consultations to follow- } \\
\text { up women after cerclage } \\
\text { insertion, reverting to the } \\
\text { minimum frequency of } \\
\text { TVUS as stated in national } \\
\text { guidelines. }\end{array}$ & $\begin{array}{l}\text { Weekly liaison across } \\
\text { sites meant regular } \\
\text { feedback from staff } \\
\text { and patients, the } \\
\text { acceptability of our } \\
\text { new care pathway. } \\
\text { Patient anxiety and } \\
\text { volume of calls made } \\
\text { to staff were noted. }\end{array}$ & $\begin{array}{l}\text { Reinstated offering FTF } \\
\text { appointments to women } \\
\text { following both history and } \\
\text { ultrasound indicated cerclages. }\end{array}$ \\
\hline
\end{tabular}

PDSA cycle D: introduction of remote consultations
We thought we could minimise non-essential FTF hospital visits.

\begin{tabular}{|c|c|c|c|c|}
\hline $\begin{array}{l}\text { PDSA cycle } \\
\text { E: procedural } \\
\text { aspects of } \\
\text { cervical cerclage } \\
\text { placement }\end{array}$ & $\begin{array}{l}\text { We wanted to reduce and } \\
\text { where possible, eliminate, } \\
\text { aerosol-generating } \\
\text { procedures, such as a GA at } \\
\text { the time of cervical cerclage } \\
\text { placement. Guidance issued } \\
\text { from Public Health England } \\
\text { guidance stated that full } \\
\text { PPE, including a water- } \\
\text { resistant gown and visor to } \\
\text { be worn for all GAs, whether } \\
\text { COVID-19 was suspected } \\
\text { or not. }\end{array}$ & $\begin{array}{l}\text { With input and direction } \\
\text { from the anaesthetists, } \\
\text { we aimed to insert } 95 \% \\
\text { of cerclages SA. Regular } \\
\text { liaison with all staff involved } \\
\text { meant we could frequently } \\
\text { gain feedback to ensure } \\
\text { best contemporary practice, } \\
\text { optimising patient and staff } \\
\text { safety. }\end{array}$ & $\begin{array}{l}20 / 21 \text { cases were } \\
\text { performed under } \\
\text { SA. } 1 / 21 \text { required } \\
\text { a GA due to } \\
\text { contraindication to } \\
\text { regional anaesthetic. } \\
\text { Regional anaesthetic } \\
\text { was found to be } \\
\text { acceptable to } \\
\text { women and staff. }\end{array}$ & $\begin{array}{l}\text { We decided to adopt this } \\
\text { practice as long as the } \\
\text { COVID-19 recommendation } \\
\text { for full PPE during GA } \\
\text { procedures were in place. It is } \\
\text { unlikely that this practice will } \\
\text { not be continued following } \\
\text { the COVID-19 outbreak as } \\
\text { regional anaesthesia increases } \\
\text { the procedure and recovery } \\
\text { duration. We also saw an } \\
\text { increase in cases of urinary } \\
\text { retention leading to prolonged } \\
\text { hospital admissions. }\end{array}$ \\
\hline
\end{tabular}

FDCS, fully dilated caesarean section; FTF, face to face; GA, general anaesthetic; PPE, personal protective equipment; SA, spinal anaesthetic; SPTB, spontaneous preterm birth; TVUS, transvaginal ultrasound.

majority of patients did not mind having remote consultations $(62.5 \%)$, and $75 \%$ were happy or had no preference for telephone over video consultations. The majority of staff $(60 \%)$ thought that the adjusted pathway minimised risk of COVID-19 exposure, spread and tramission and also thought that it reduced workload in the preterm prevention clinic. Furthermore, $80 \%$ stated that the new pathway was effective in identifying women who may require a cerclage, although all staff highlighted that less survillence had increased anxiety levels for patients. This 
Table 2 Risk factors for PTB that require referral to the clinic in light of COVID-19 restructure

\begin{tabular}{|c|c|}
\hline High risk & Intermediate risk \\
\hline $\begin{array}{l}\text { Previous PTB/PPROM } \\
\text { (<34+0 weeks) }\end{array}$ & $\begin{array}{l}\text { Previous excisional cervical } \\
\text { treatment }>10 \mathrm{~mm} \text { depth }\end{array}$ \\
\hline Previous MTL (>16 weeks + ) & $\begin{array}{l}\text { Previous > } 1 \text { excisional } \\
\text { treatment or cone biopsy }\end{array}$ \\
\hline $\begin{array}{l}\text { Incidental finding of a short/ } \\
\text { open cervix }\end{array}$ & Previous FDCS* \\
\hline
\end{tabular}

FDCS, fully dilated caesarean section; MTL, mid-trimester loss; PPROM, preterm prelabour rupture of membranes; PTB, preterm birth.

was shared by women when asked about their preference after the outbreak is over, only $6.25 \%$ would be happy for remote consultations. This reflects the balance that was needed to manage raised anxiety caused to women in not having a transvaginal ultrasound following their cerclages, with risk of attendance to the clinic during the COVID-19 outbreak. Staff reported an increase in telephone calls from women who had received a cervical cerclage seeking further reassurance. Therefore, using our PDSA model (C) cycle (table 1), we reinstated FTF follow-up consultations instead of telephone consultations for women who had cerclage as treatment, increasing the number of our FTF consultations from 11 May, as seen in peak at week 19 in the graph (figure 2).

\section{Change in procedural aspects during cerclage insertion}

Prior to the COVID-19 outbreak, the anaesthetic used for the insertion of a cerclage was predominantly a GA if women were $<16$ weeks pregnant and an SA for women $>16$ weeks pregnant as based on the recommendation of the anaesthetist. The rate of GA was $47 \%$ and SA was $53 \%$ in the baseline pre-COVID-19 period (figure 3C). However, following the introduction of the need to use

\begin{tabular}{|l|c|c|c|c|}
\hline A & $\begin{array}{l}\text { Pre-COVID-19 } \\
\text { 10 weeks }\end{array}$ & $\begin{array}{l}\text { COVID-19 outbreak } \\
\text { 10 weeks }\end{array}$ & change & P value \\
\hline $\begin{array}{l}\text { Number of clinic } \\
\text { consultations }\end{array}$ & 341 & 378 & $+10 \%$ & n/a \\
\hline $\begin{array}{l}\text { Number of FTF } \\
\text { consultations }\end{array}$ & 341 & 157 & $-53.9 \%$ & $<0.0001$ \\
\hline $\begin{array}{l}\text { Number of phon } \\
\text { consultations }\end{array}$ & 0 & 221 & $+64.8 \%$ & $<0.0001$ \\
\hline
\end{tabular}

B Pre-CovID-19 clinic consultations

C COVID-19 outbreak clinic consultations
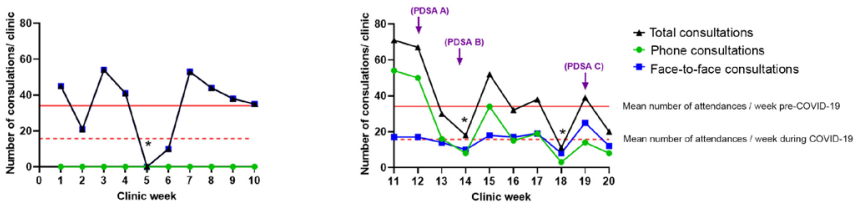

Figure 2 Reduction in face-to-face (FTF) consultations in the preterm prevention clinic during the COVID-19 outbreak. During the COVID-19 outbreak, we introduced remote consultations, with a target of $20 \%$ reduction of FTF visits. We reduced FTF visits by $53.9 \%(p<0.001)$ and increased telephone consultations by $64.8 \%(p<0.0001)$ compared with the pre-COVID-19 study period (A). The run chart shows the number of FTF consultations in the pre-COVID-19 comparator period, with a mean of 34.1 women seen per week cross-site (B). During the COVID-19 pandemic, we reduced FTF consultations to a mean of 15.1 women per week cross-site (C). Statistical analysis was performed using the Fisher's exact test. The trophs with a star $\left(^{*}\right)$ represents the weeks affected by cancelled clinics $(n=719)$. PDSA, Plan Do Study Act; n/a, not available.

full personal protective equipment in cases where a GA is administered even for asymptomatic patients the results of our staff and patient surveys that fed into our PDSA cycle (table 1) revealed that a target of $95 \%$ cases being performed under SA would be feasible. Eighty-eight per cent of our staff surveyed preferred to introduce SA unless clinically contraindicated (figure 3B). Despite there not being an overall preference for SA in our patient survey, importantly, there was no overall preference seen for receiving a GA (figure $3 \mathrm{~A}$ ). We successfully met our target of $95 \%$ with only $1 / 21$ woman receiving a GA. This single

Table 3 Appointment schedule in light of COVID-19 restructure

Previous PTB $(<34+0$ weeks)

And/or previous MTL

And or cone biopsy
First appointment as telephone consultation.

Recommend one CL scan between 16 and 20 weeks, however: If $\mathrm{CL}>35 \mathrm{~mm}$, follow-up appointments as telephone consultation; If CL 25-34 mm for follow-up FTF;

If $\mathrm{CL}<25 \mathrm{~mm}$ for cerclage and telephone follow-up. Discharge at $26+0$.

Incidental finding of a short or open cervix

Telephone consultation to replace FTF consultation postcerclage. If anxious, for continued FTF until 26 weeks*.

History of excisional cervical treatment $>10 \mathrm{~mm}$ depth or $>1$ excisional treatment or cone biopsy

Previous FDCS*

Previous cervical cerclage

Cervical cerclage in current pregnancy
First appointment as telephone consultation.

Recommend two CL scans between 16 and 24 weeks, refer back to routine care if $\mathrm{CL}>35 \mathrm{~mm}$ at 24 weeks.

Telephone consultation or FTF \pm elective cerclage.

No FTF follow-up.

If anxious, for continued FTF until 26 weeks*.

*Amendments following the PDSA cycle reviews are in bold.

CL, cervical length; FDCS, fully dilated caesarean section; FTF, face to face; MTL, mid-trimester loss; PDSA, Plan Do Study Act; PTB, preterm birth. 
A
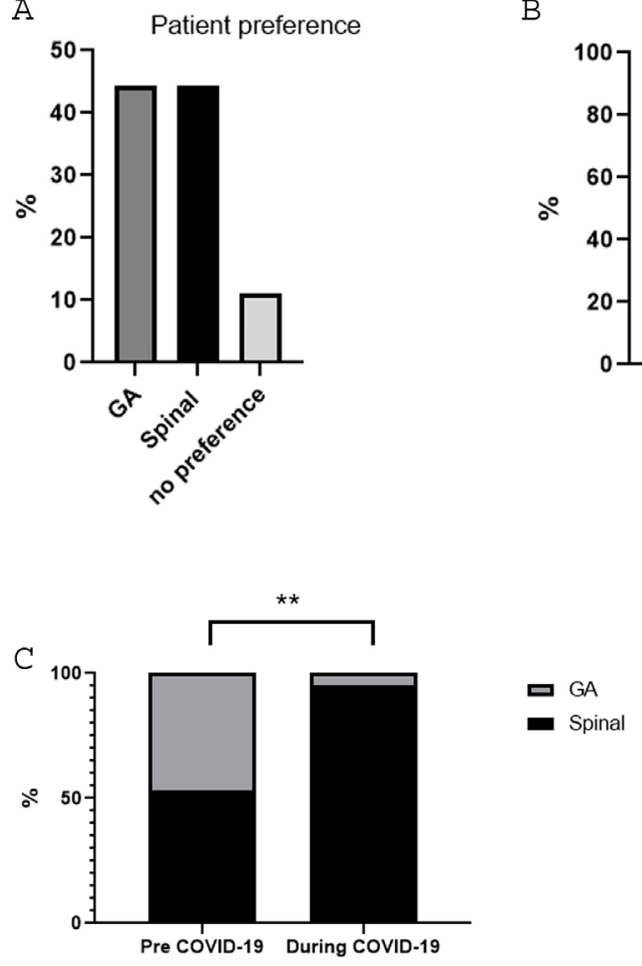

Figure 3 Reduction in general anaesthetic use in women receiving a cervical cerclage during the COVID-19 outbreak. There was no overall difference in patient preference for the type of anaesthesia used for cerclage (A), however $88 \%$ of staff preferred a spinal anaesthetic in order to reduce the number of aerosol-generating procedures (B). Therefore, during the COVID-19 outbreak, we altered practice and recommended that women should undergo the procedure under spinal anaesthetic, and we increased the frequency of use of spinal anaesthesia from $53 \%$ to $95 \%$ during the study period (C). Statistical analysis was performed using the Fisher's exact test. $P=0.004, n=36$ patient questionnaire (A), 9 staff questionnaire (B) and 21 who had a cerclage (C). Statistical analysis was performed using the Fisher's exact test. ${ }^{* *}=p<0.01 . n=36$ patient questionnaire $(A), 9$ staff questionnaire $(B)$ and 21 who had a cerclage $(C)$.

case requiring GA was due to a clinical contraindication to regional anaesthesia (figure 3C).

\section{LESSONS, STRENGTHS AND LIMITATIONS}

As the COVID-19 outbreak evolved in the UK, we used QI principles to provide a framework to evaluate the rapid implementation of an altered care pathway for women at risk of sPTB. Our overall aim was to rapidly implement a care pathway that would reduce exposure, transmission and spread of SARS-COV-2, while maintaining a high quality of care for women at risk of sPTB.

We refined the referral criteria and excluded women with a history of congenital uterine anomalies (CUAs) and previous FDCS. Our rationale for excluding women with a CUA drew on results from a retrospective cohort of 319 women with CUA, of which a large proportion was seen at our trust between 2014 and 2016. ${ }^{11}$ We reported that the sPTB rate $<37$ weeks of women with CUA as their sole risk factor was $12.8 \%$, and that CL was a poor predictor of sPTB $<37$ weeks (area under the curve 0.56 (95\% CI 0.48 to 0.64 ), with a low sensitivity of 15.2 . Despite there being a reported association between sPTB and a history of FDCS, with rates of sPTB being reported as $41 \%{ }^{12}$ and $13.5 \%{ }^{13}$ in two studies, the numbers of these studies are small ( $<40$ cases of FD section in each study). Furthermore, a larger retrospective study comparing 23072 women following a caesarean section in the first stage of labour with 8607 women who had a caesarean section in the second stage reported $\mathrm{SPTB}$ delivery rates of $3.2 \%$ and $5.3 \%$, respectively. ${ }^{14}$ The Cerclage after full dilatation caesarean section (CRAFT) study is addressing the uncertainty of risk and the efficacy of CL monitoring and cerclage in women with a previous FDCS (https:// www.kcl.ac.uk/research/craft). Although we initially excluded these women from the referral criteria, we reinstated it after identifying a woman requiring an emergency cerclage with previous FDCS as her only risk factor. The benefits of having a QI framework and action team allowed us to rapidly reinstate this as local guidance.

Although the number of referrals increased, and the number of inappropriate referrals did not reduce over the COVID-19 period, both the absolute number and the percentage of FTF consultations significantly reduced beyond our initial target stated in our SMART objectives. With the increased communication to maternity staff on guidelines and protocols during the COVID-19 outbreak, it is plausible that this led to an increase in referrals due to the increased publicity of the service. One explanation for not reducing the number of inappropriate referrals was due to the difficulty in effectively publishing the changes to our clinic inclusion criteria. Over this time period, there were many guideline updates and emails so it was understandably difficult for the referring midwives and doctors to keep up to date with all changes. Nevertheless, the PDSA cycle (table 1) highlighted the need for clinicians to vet all referrals in order to reduce the number of FTF appropriate and inappropriate consultations. Clinician vetting, as already mentioned was initially a time-consuming process. The increase in referrals, alongside the need to adjust existing clinic templates, and contact all patients affected by changes, placed additional strain on clinic time. However, once implemented, the reduction in inappropriate referrals attending the clinic for FTF consultations has balanced this out. We therefore believe that this change is beneficial and sustainable.

We used QI strategies, PDSA and feedback from stakeholders in the form of patient and staff questionnaires to evaluate the introduction of remote consulting. We achieved a higher rate of remote consulting (64\%). Our evaluation drew on similar QI strategies used by Gilbert et al, where they also exceeded their remote consulting target during the COVID-19 outbreak at the Royal National Orthopaedic Hospital. ${ }^{15}$ However, their patient satisfaction for remote consulting was higher at $90 \%$ compared with $62.5 \%$ in our study. Staff opinion from our multidisciplinary team was also important in implementing the new care pathway. This was especially 
the case regarding altering standard practice to recommend spinal anaesthesia (unless medically contraindicated) to all women having a cerclage. Staff perceived that reducing the number of aerosol-generating procedures could reduce the risk of transmission among staff. Although there was no strong patient preference on type of anaesthesia, staff preference was relied on in evaluating improvement in our change in standard practice. Whether or not this change will be sustained will depend on the ongoing influence of COVID-19 on hospital policies as well as staff and patient preferences.

The strengths of this project included:

- Use of validated QI methods from the outset.

- Access to high-quality baseline data to inform our change ideas, and ongoing regular data review and response using PDSA cycles.

- Several PDSA cycles over the short period in order to make rapid adjustments to the care pathway.

- A team-based approach between the PTB prevention team and QI Imperial College Healthcare trust staff across both maternity sites.

- Involvement of stakeholders from the outset by use of patient and staff questionnaires.

By using the QI methodology, our study along with others ${ }^{16}$ can be used as a framework to adapt, modernise and even re-open services following the COVID-19 outbreak.

The main limitation of this QI project is that we cannot demonstrate with absolute certainty that the new care pathway did not result in an increase in potentially preventable MTLs or PTBs. Furthermore, it is possible that by reducing our FTF consultations and refining our referral criteria we may have missed women that could have benefited from CL monitoring and a cervical cerclage. This was highlighted as one woman who had a history of previous FDCS was not initially seen with the COVID-19 pathway yet presented with a short cervix requiring cerclage at the time of her anomaly scan. However, the benefits of having a QI framework and action group in regular contact led us to be able to rapidly update our COVID-19 care pathway and improve the standard of care provided to our patients. Of the 221 women who were cared for during the study period, and of which outcome data are available, the PTB rate $<37$ weeks was $17.7 \%$ and the sPTB rate was $12.6 \%$. This was comparable with the 3-year average in our clinic of $18.8 \%$ and $13.4 \%$ for PTB and SPTB, respectively. This implies that our altered care pathway did not compromise care.

The sustainability of the altered care pathway has been proven as the Imperial preterm prevention team enter the second lockdown at the time of manuscript acceptance. Guidance was issued from NHS England to reduce PTB during COVID- $19^{18}$ after our study period. This recommended altered care pathways which we had already implemented, encouraging the use of remote consultations and reduced frequency of FTF appointments, which we have demonstrated is sustainable as we continue into the second lockdown. In addition, we have maintained our reduced use of GA, although it has become more commonly used due to the development of routine COVID-19 testing for electives admissions. Shortly before the second lockdown the Royal College of Obstetricians and Gynaecologists (RCOG) ${ }^{19}$ also released new guidance, stating antenatal care should continue in full, as much as possible, highlighting the effectiveness of FTF consultations. This is highlighted in our caseload of women who have had cerclages and return for reassurance scans, a revised feature of our pathway in PDSA cycle C (table 1).

\section{CONCLUSION}

This QI project allowed the PTB prevention service to ensure efficient and rapid alterations to care provision for women at high risk of PTB during the COVID-19 pandemic. We successfully reduced the number of FTF visits for our women attending the PTB clinic and reduced the number of cervical cerclage procedures done under GA. Although it would be impossible to directly link our measures on COVID-19 infection rate, our measures have reduced the potential for exposure for staff and patients. We had no reported cases of COVID-19 in our clinic population. Areas of improvement were identified and implemented using PDSA cycles with a dedicated multidisciplinary team of doctors, midwives, administrative and managerial staff. To our knowledge, this is the first QI project from a PTB prevention service in the COVID-19 pandemic and provides a model of care that can be applied to PTB services, globally. In the case of a second peak or future pandemic, our service is equipped to adapt immediately with evidence of safety and efficiency.

Correction notice This article has been corrected since it first published. The provenance and peer review statement has been included.

Twitter Sabrina Das @drsabrinadas and Lynne Sykes @DrLynneSykes

Acknowledgements The authors would like to thank the study participants and our Imperial Patients as Partners PPI group for their contribution.

Contributors LS, SZ, SD and KJ designed the study. MA, EB, KM, HL, LS and SZ were involved in data collection. SZ, LS and SD performed the data analysis. SZ and LS drafted the manuscript. All authors revised the manuscript. LS is the guarantor of the manuscript.

Funding This work was supported by the National Institute for Health Research Comprehensive Biomedical Research Centre at Imperial College Healthcare NHS Trust and Imperial College London. This work and MA, PRB and LS were also supported by The March of Dimes.

Disclaimer The views expressed are those of the authors and not necessarily those of Imperial College, the NHS, the NIHR or the Department of Health.

Competing interests None declared.

Patient and public involvement Patients and/or the public were involved in the design, or conduct, or reporting, or dissemination plans of this research. Refer to the 'Methods and design' section for further details.

Patient consent for publication Not required.

Provenance and peer review Not commissioned; externally peer reviewed.

Data availability statement Data are available on reasonable request.

Open access This is an open access article distributed in accordance with the Creative Commons Attribution Non Commercial (CC BY-NC 4.0) license, which permits others to distribute, remix, adapt, build upon this work non-commercially, and license their derivative works on different terms, provided the original work is 
properly cited, appropriate credit is given, any changes made indicated, and the use is non-commercial. See: http://creativecommons.org/licenses/by-nc/4.0/.

ORCID iD

Lynne Sykes http://orcid.org/0000-0002-7806-5707

\section{REFERENCES}

1 World Health Organisation. Coronavirus disease 19 situation report 51, 2020. Available: https://www. who. int/ docs/ default- source/ coronaviruse/ situation- reports/20200311- sitrep- 51- covid- 19 pdf? sfvrsn= 1ba62e57_ 10

2 Public Health England. COVID-19: guidance on social distancing and for vulnerable people, 2020. Available: https://www.gov. uk/ government/publications/covid-19-guidance-on-social-distancingand-for-vulnerable-people [Accessed 17 March 2020].

3 Royal College of Obsetricians and Gynaecologists. Coronavirus (COVID-19) infection in pregnancy version 2, 2020. Available: https:// www.rcog.org.uk/en/guidelines-research-services/coronavirus-covid19-pregnancy-and-womens-health/ [Accessed 13 Mar 2020].

4 Mullins E, Evans D, Viner RM, et al. Coronavirus in pregnancy and delivery: rapid review. Ultrasound Obstet Gynecol 2020;55:586-92.

5 Verity R, Okell LC, Dorigatti I, et al. Estimates of the severity of coronavirus disease 2019: a model-based analysis. Lancet Infect Dis 2020;20:669-77.

6 Liu L, Oza S, Hogan D, et al. Global, regional, and national causes of under-5 mortality in 2000-15: an updated systematic analysis with implications for the sustainable development goals. Lancet 2016;388:3027-35.

7 NHS England. Saving babies' lives version two: a care bundle for reducing perinatal mortality, 2019. Available: https://www.england. nhs.uk/publication/saving-babies-lives-version-two-a-care-bundlefor-reducing-perinatal-mortality/

8 Royal College of Obsetricians and Gynaecologists. Guidance for antenatal and postnatal services in the evolving coronavirus (COVID-19) pandemic version 1, 2020. Available: https://www.rcog org.uk/globalassets/documents/guidelines/2020-05-22-guidance-forantenatal-and-postnatal-services-in-the-evolving-coronavirus-covid19-pandemic.pdf [Accessed 30 Mar 2020].
9 NHS England. Guidance for maternity services regarding fetal growth surveillence and management during the coronavirus pandemic, 2020. Available: https://www.england.nhs.uk/publication/savingbabies-lives-care-bundle-version-2-covid-19-information/ [Accessed April 2019].

10 NHS England. COVID-19 and CO monitoring. Available: https://www. england.nhs.uk/publication/saving-babies-lives-care-bundle-version2-covid-19-information/ [Accessed April 2019].

11 Ridout AE, Ibeto LA, Ross GN, et al. Cervical length and quantitative fetal fibronectin in the prediction of spontaneous preterm birth in asymptomatic women with congenital uterine anomaly. Am J Obstet Gynecol 2019;221:341.e1-341.e9.

12 Watson HA, Carter J, David AL, et al. Full dilation cesarean section: a risk factor for recurrent second-trimester loss and preterm birth. Acta Obstet Gynecol Scand 2017;96:1100-5.

13 Levine LD, Sammel MD, Hirshberg A, et al. Does stage of labor at time of cesarean delivery affect risk of subsequent preterm birth? Am J Obstet Gynecol 2015;212:360.e1-360.e7.

14 Wood SL, Tang S, Crawford S. Cesarean delivery in the second stage of labor and the risk of subsequent premature birth. Am J Obstet Gynecol 2017;217:63.e1-63.e10.

15 Gilbert AW, Billany JCT, Adam R, et al. Rapid implementation of virtual clinics due to COVID-19: report and early evaluation of a quality improvement initiative. BMJ Open Qual 2020;9:e000985.

16 Duska LR, Mueller J, Lothamer $\mathrm{H}$, et al. Lean methodology improves efficiency in outpatient academic gynecologic oncology clinics. Gynecol Oncol 2015;138:707-11.

17 Moore S, Arthur R. A quality improvement initiative: using lean methodology to improve efficiency of the morning cycle monitoring at an ambulatory academic fertility clinic. J Obstet Gynaecol Can 2019;41:755-61.

18 NHS England. Implications of COVID-19 on reducing preterm births. Available: https://www.england.nhs.uk/wp-content/uploads/2020/04/ C0499-Appx-I-to-SBLCBv2-Reducing-preterm-births.pdf [Accessed Nov 2020].

19 Guidance for antenatal and postnatal services in the evolving coronavirus (COVID-19) pandemic, 2020. Available: https://www. rcog.org.uk/globalassets/documents/guidelines/2020-10-21guidance-for-antenatal-and-postnatal-services-in-the-evolvingcoronavirus-covid-19-pandemic-v3.pdf 